\title{
Perancangan MP3 Player dengan Visual C\# 2010
}

\author{
Megawaty ${ }^{1)}$, Nia Oktaviani ${ }^{2)}$ \\ Universitas Bina Darma \\ Jalan Jenderal Ahmad Yani No.12 Palembang \\ Megawaty.UBD@gmail.com ${ }^{1)}$,nia240486@gmail.com ${ }^{2)}$
}

\begin{abstract}
Di era modern ini kehidupan manusia hampir tidak dapat dipisahkan dengan musik. Perkembangan dunia digital pun cukup berpengaruh terhadap perkembangan musik. MP3 merupakan format file musik yang sangat banyak diminati karena ukuran filenya yang kecil namun memiliki kualitas suara yang cukup bagus. Seiring perkembangan teknologi, kita bisa mendengarkan musik dengan berbagai macam perangkat seperti mobile phone, laprop, komputer, Music player dan lain-lain. Saat ini banyak sekali program MP3 Player yang disediakan oleh para pengembang baik yang bersifat gratis maupun berbayar. Kebanyakan orang hanya bergantung pada program yang sudah ada pada sistem operasi yang mereka install pada perangkat komputer mereka. Sehingga ide-ide kreatif para mahasiswa terutama pada bidang design user interface kurang berkembang. Kali ini akan dideskripsikan bagaimana merancang suatu program MP3 Player yang dapat digunakan pada perangkat komputer dengan sistem operasi windows 7 atau windows 8. Dengan merancang Program MP3 Player dengan Visual C\# 2010 ini, diharapkan para mahasiswa dapat membuat sendiri MP3 Player yang sederhana dan sesuai dengan keinginannya. Bahasa pemodelan UML memiliki beberapa konsep dasar yang merupakan standar dalam berbagai pendekatan dalam solusi pemodelan. Konsep-konsep tersebut digunakan dalam penyeragaman analisa, perancangan, dan implementasi berbagai sistem perangkat lunak. Dengan menggunakan UML ini sebagai tools akan lebih memudahkan baik dalam perancangan maupun dalam memahami kebutuhankebutuhan user pada suatu program.
\end{abstract}

Keywords-MP3 Player, Visual C\# 2010

\section{INTRODUCTION}

Saat ini hampir semua orang dari berbagai kalangan mengenal file MP3. Terutama masyarakat perkotaan. Dengan ukuran filenya yang kecil orang-orang akan dapat mendengarkan berbagai judul lagu dalam suatu media penyimpanan. Hal inilah yang membuat file MP3 cukup digemari untuk digunakan. Untuk dapat mendengarkan atau menjalankan file MP3 ini kita memerlukan suatu program berupa MP3 player.

MP3 atau (Motion Picture Experts Group Audio Layer3/MPEG Audio Layer-3) adalah kompresi audio codec yang dapat digunakan dengan perangkat komputer ataupun perangkat elektronik lain. MP3 telah distandarisasi dengan Moving Picture Experts Group (MPEG) untuk digunakan sebagai skema kompresi kualitas tinggi, dengan menggunakan teknik encoding yang dapat mencapai rasio kompresi hingga 12:1 dibandingkan dengan CD Audio.

Dengan ukuran yang relatif kecil, file MP3 lebih efisien pada penggunaan harddisk komputer dan menjadi standar penggunaan musik terutama di internet. (Raphael Kang, MP32000.com : 27 Mei 2001)

Visual C\# (dibaca: C sharp) merupakan sebuah bahasa pemrograman yang berorientasi objek yang dikembangkan oleh Microsoft sebagai bagian dari inisiatif kerangka .NET Framework. Bahasa pemrograman ini dibuat berbasiskan bahasa $\mathrm{C}++$ yang telah dipengaruhi oleh aspek-aspek ataupun fitur bahasa yang terdapat pada bahasa-bahasa pemrograman lainnya seperti Java, Delphi, Visual Basic, dan lain-lain) dengan beberapa penyederhanaan. Menurut standar ECMA334 C\# Language Specification, nama C\# terdiri atas sebuah huruf Latin C (U+0043) yang diikuti oleh tanda pagar yang menandakan angka \# (U+0023). Tanda pagar \# yang digunakan memang bukan tanda kres dalam seni musik $(\mathrm{U}+266 \mathrm{~F})$, dan tanda pagar \# $(\mathrm{U}+0023)$ tersebut digunakan karena karakter kres dalam seni musik tidak terdapat di dalam keyboard standar.

Tujuan dari penelitian ini adalah untuk merancang MP3 Player dengan Visual C\# 2010.

\section{LANDASAN TEORI}

Unified Modeling Language

Pada awal tahun 1990-an mulai muncul berbagai macam metode-metode yang digunakan dalam dunia pengembangan perangkat lunak sebagai metodologi analisis dan perancangan perangkat lunak yang berbasiskan objek. Dari perkembangan metodologi yang telah digunakan sebelumnya, maka saat ini telah menjadi standar dunia internasional dalam metodologi analisis dan perancangan perangkat lunak yang berbasiskan objek tersebut adalah Unified Modeling Language (UML). Bahasa pemodelan UML ini memiliki beberapa konsep dasar yang merupakan standar dalam berbagai pendekatan dalam solusi pemodelan. Konsepkonsep tersebut digunakan dalam penyeragaman analisa, perancangan, dan implementasi berbagai sistem perangkat lunak. 
Pendekatan object oriented menggunakan lima konsep dasar untuk penyeragaman analisa, perancangan dan implementasi berbagai sistem perangkat lunak.

\section{Objek}

Objek merupakan suatu entitas yang memiliki atribut, perilaku, dan identitas. Bentuk umum dari suatu objek adalah :

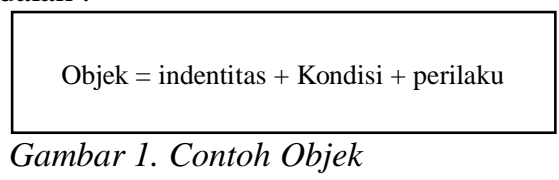

a. Identitas adalah karakteristik unik dari setiap objek yang membedakan objek yang satu dengan yang lainnya.

b. Kondisi merupakan pengelompokkan keseluruhan atribut .

c. Perilaku merupakan kemampuan suatu objek untuk melakukan suatu aksi atau respon.

2. Pesan (message)

Pesan adalah unit komunikasi antar objek, yang merupakan dasar dalam hubungan relasi antar objek yang dinamis. Pesan akan membentuk kumpulan objek menjadi suatu bentuk penggabungan.

3. Kelas

Kelas adalah representasi objek dalam sebuah sistem. Objek adalah contoh langsung dari suatu kelas. Contoh dari kelas ditunjukkan pada Gambar 1 dibawah ini.

\begin{tabular}{|l|}
\hline \multicolumn{2}{|l|}{ TombolPlayback } \\
\hline- Play \\
\hline+ push () \\
\hline$+\operatorname{push}()$ \\
\hline
\end{tabular}

Gambar 2.. Kelas tombol playback

\section{PERANCANGAN}

Perancangan dengan UML

Pada perancangan MP3 Player, pemodelan dengan UML digunakan untuk mengidentifikasi serta menganalisa sistem dan kebutuhan sistem yang diperlukan agar dalam proses pembuatan program MP3
Player menjadi lebih baik, efisien, dan terarah. Untuk menganalisa permasalahan dimodelkan dalam diagram use case, tujuannya untuk mengamati

bagaimana perilaku sistem yang diinginkan dilihat dari sudut pandang pengguna (user). Selanjutnya

dikembangkan dengan pemodelan diagram kelas. Pada diagram kelas, fitur-fitur yang diinginkan dimodelkan menjadi objek-objek. (Rosa \& Shalahudin, Rekayasa perangkat lunak terstruktur dan berorientasi objek).

Modula:Bandung (2011).

Pada proses perancangan digunakan pemodelan diagram sequence dan diagram kolaborasi. Diagram sequence menggambarkan interaksi antar objek dalam suatu rangkaian waktu. Diagram sequence akan memperjelas setiap use case yang memiliki lebih dari satu objek.

Dalam proses pembuatan program, detail diagram kelas akan memberikan gambaran yang lebih jelas terhadap sistem yang akan dibuat. Diagram aktivitas digunakan sebagai panduan dalam penyusunan algoritma program yang menggambarkan operasi pada suatu objek atau proses yang berlangsung.

1. Permasalahan

Pada tahap ini harus dipahami betul permasalahan yang dihadapi untuk mencari solusi yang tepat dan efisien. Didefinisikan satu permasalahan adalah bagaimana membuat perangkat lunak yang dapat menjalankan file lagu dengan format mp3. Secara lengkap permasalahan tersebut adalah sebagai berikut :

a.Tombol playback untuk menjalankan file-file mp3 seperti play, pause, stop, next, dan juga previous.

b.Tombol file untuk pengaturan file-file mp3 seperti open file, add file, add folder, delete, serta clear.

c.Editor file mp3 untuk memilih file mp3 yang ingin dijalankan dan memilih file yang akan di delete.

d.Track untuk mengatur volume, balance, dan juga equalizer.

e.Panel yang menginformasikan tentang file mp3 yang sedang dijalankan, seperti durasi waktu, waktu lewat, info lagu, mode lagu, dan status player.

2. Analisa Permasalahan

Pada segmen analisis permasalahan, yaitu merinci lebih dalam dokumentasi telah diperoleh pada proses sebelumnya. Pemodelan diagram use case digunakan 
untuk menganalisa interaksi antar use case. Serta diagram kelas yang menunjukkan relasi diantara objek.

\section{a.Diagram Use Case}

Dengan diagram use case dapat diperoleh gambaran mengenai kebutuhan sistem yang akan digunakan dan juga memberi gambaran tentang fungsi yang dikehendaki pada saat sistem dijalankan. Diagram use case dapat dilihat pada Gambar 6 berikut :

Dari pemodelan diagram pada Gambar 6 dapat diterjemahkan proses yang diinginkan. Prosesproses tersebut adalah sebagai berikut :

1.Pada tampilan utama, user menekan tombol open untuk memasukan file mp3 pada playlist mp3.

2.File mp3 yang telah dipilih akan muncul pada playlist mp3.

3.Setelah memilih salah satu file mp3, user dapat menjalankan tombol playback seperti play, pause, stop, next, previous.

4.Hasil akhir dari keseluruhan proses yang telah berlangsung adalah keluaran MP3 Player yaitu file mp3 yang dapat didengarkan oleh user.

\section{b.Diagram Class}

Setiap objek yang dikehendaki dimodelkan menjadi suatu kelas. Kelas-kelas akan saling berelasi dan berinteraksi untuk membentuk suatu sistem.

Kelas Windows media player merupakan pusat pengendalian sistem secara keseluruhan. Tombol playback dan tombol file memiliki hubungan asosiasi dengan Windows media player karena berfungsi untuk menjalankan filefile mp3 yang dipilih. Begitu juga dengan File mp3, Equalizer dan Kontrol Suara akan saling berinteraksi dalam sistem yang akan dibuat. Sedangkan slider, panel waktu, info lagu dan status player merupakan panel yang menginformasikan mengenai proses yang sedang berlangsung.

3.

4. Proses Perancangan

Dalam segmen ini bertujuan untuk merancang solusi dari permasalahan yang telah dianalisa sebelumnya. Pada tahap perancangan ini memberikan suatu model diagram yang lebih detail/terperinci sebagai acuan dalam proses pembuatan sistem yang diinginkan.

\section{a.Diagram Sequence}

Pada diagram sequence ditunjukkan bahwa user sebagai operator bagi MP3 Player, dapat mengatur proses yang diinginkan, seperti play, pause, dan stop file mp3. User juga dapat mengatur equalizer dan kontrol suara sesuai dengan seleranya. Pengaturan oleh user diatas akan dilaksanakan oleh Windows media player. Semua pengaturan yang dilakukan oleh user dapat diketahui melalui informasi yang terdapat pada tampilan utama, antara lain panel status player, panel waktu, info lagu dan juga slider.

\section{b.Diagram Kolaborasi}

Pemodelan dengan diagram kolaborasi hampir sama dengan diagram sequence. Pada diagram kolaborasi ini lebih memfokuskan pada hubungan antara objekyang dikumpulkan menjadi suatu keterkaitan yang utama. Seperti dapat dilihat pada Gambar 9 di bawah, masingmasing objek memiliki hubungan yang begitu terkait dengan objek lain untuk menjalankan sistem yang dirancang.

\section{PEMBUATAN APLIKASI}

Dalam proses perancangan model sebelumnya telah diperoleh dokumentasi mengenai konsep serta analisa kebutuhan sistem yang diperlukan dalam pembuatan MP3 Player. Langkah selanjutnya adalah membuat pemodelan diagram kelas yang lebih detail, dan juga merancang bentuk atau tampilan utama MP3 Player.

\section{Detail Diagram kelas}

Detail diagram kelas yang penulis sajikan merupakan model yang memberikan informasi lebih lengkap baik mengenai kebutuhan sistem dan juga sistem aplikasi yang akan dibuat.

2.Memulai menjalankan Visual C\# 2010

Memulai Visual C\#, lalu buat sebuah project baru dengan nama project yang kita inginkan. Lalu masukkan semua objek dan query yang dibutuhkan sesuai dengan fungsi masingmasing. Utama adalah objek WMP.dll sebagai sumber atau library dari semua fungsi tombol playback dan MP3 Player kita. 


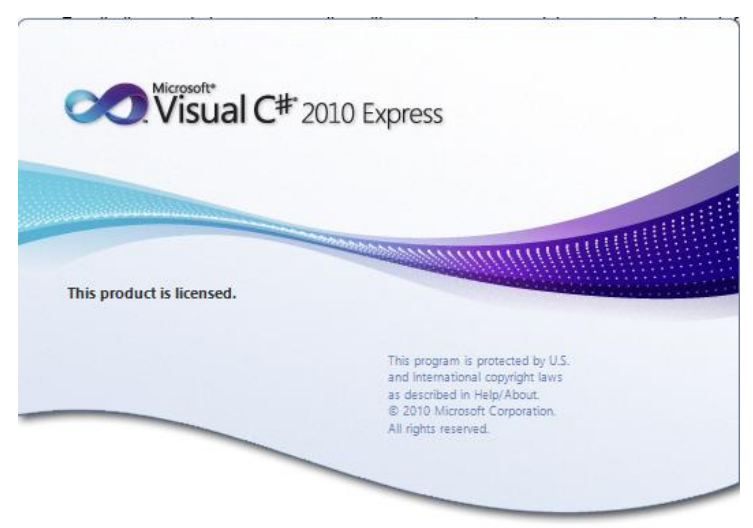

Gambar 7. Tampilan Awal Visual C\#

\section{Merancang Tampilan Utama}

Pada tampilan utama akan memuat berbagai fasilitas yang diperlukan oleh sebuah MP3 Player, antara lain tombol Playback seperti tombol play, pause, stop, next, dan previous. Kemudian tombol file seperti open file, playlist, dan untuk menghapus file mp3 (drop).

\section{Algoritma}

Menentukan algoritma fungsi dari setiap komponen pada tampilan utama. Menentukan array untuk menyimpan nama file dalam bentuk string sehingga WMP.dll dapat membuka file source. Deklarasi fungsi setiap tombol agar dapat berubah ketika kursor mendekati tomboltombol tersebut. Menentukan fungsi tombol pada saat sebuah tombol di tekan maka akan menghasilkan suatu eksekusi seperti open, play, pause, next, previous, playlist, dan drop.

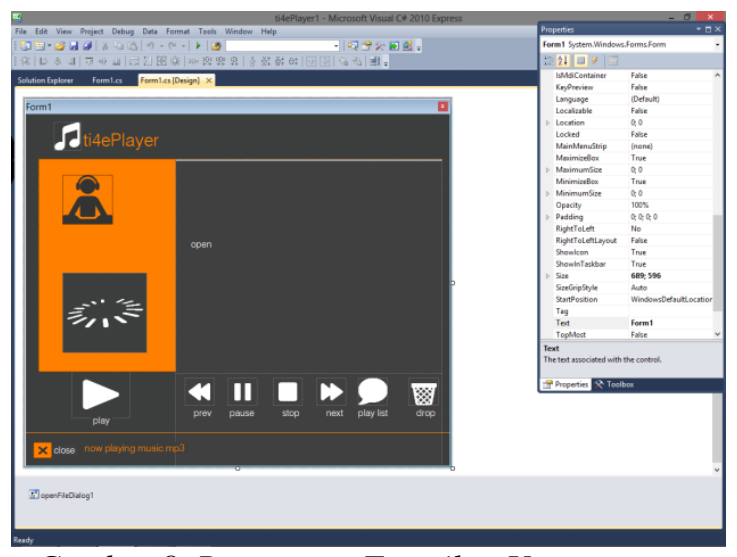

Gambar 8. Rancangan Tampilan Utama

Untuk mengetahui informasi file mp3 yang sedang dijalankan dapat dilihat pada panel info lagu, waktu lewat dan durasi waktu. Fungsi slider sebagai asesoris tambahan akan menjadikan tampilan utama lebih menarik karena slider tersebut bergerak dari kiri ke kanan sesuai dengan waktu yang sedang berjalan pada saat file mp3 dijalankan.

5.Detail Pembuatan Aplikasi

Detail pembuatan aplikasi ini adalah proses utama pembuatan program MP3 Player. Setelah tampilan utama yang diinginkan dibuat, selanjutnya adalah membuat prosedur-prosedur program agar objek yang ada pada tampilan utama dapat berjalan sesuai dengan yang diinginkan. Pada proses ini Penulis memodelkan setiap proses dalam diagram aktivitas. Setiap tombol dibuat suatu model diagram aktivitas sendiri-sendiri.

\section{IMPLEMENTASI PROGRAM}

Implementasi program MP3 Player yang telah dibuat dilakukan pada sebuah perangkat komputer multimedia. MP3 Player ini memiliki fitur atau fasilitas yang bagi user dalam mengoperasikan program seperti tombol-tombol playback, juga tombol untuk penambahan serta pengurangan file. Proses instalasi program MP3 Player sangat mudah dilakukan, yaitu dengan melakukan doubleclick pada file Setup.Exe yang terdapat di dalam direktori End Project. Selanjutnya mengikuti perintah yang terdapat pada tampilan instalasi program, dengan menekan tombol next untuk melanjutkan proses instalasi dan memilih lokasi direktori pada hard disk untuk file yang sedang diinstall. Setelah proses instalasi selesai, yang ditandai dengan indikator finish, maka program PlayerMP3.Exe sudah dapat dijalankan.

\section{PENGUJIAN PROGRAM}

Pada saat file PlayerMP3.Exe dieksekusi, maka tampilan utama akan muncul seperti pada gambar 12 berikut ini : 


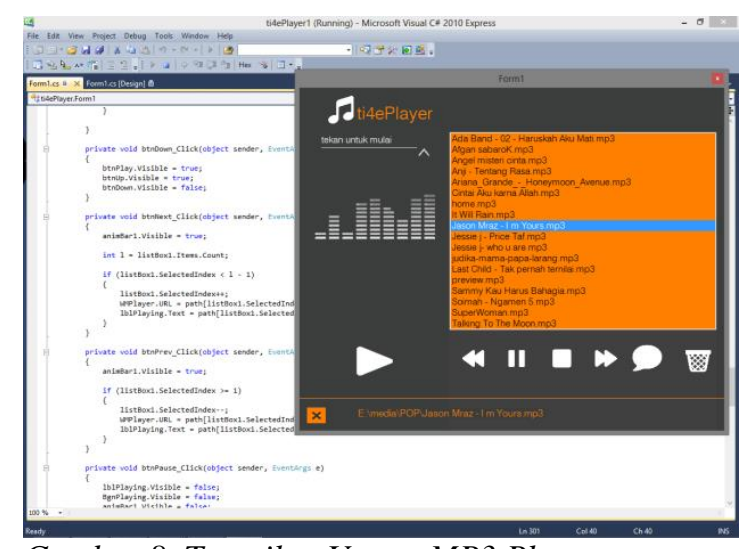

Gambar 8. Tampilan Utama MP3 Player

Untuk melihat dan menganalisa kemampuan serta fungsi yang terdapat pada MP3 Player, dilakukan pengujian terhadap program yang dibuat secara keseluruhan. Tujuannya adalah untuk mencari kesalahan yang mungkin muncul akibat salah penulisan program atau penempatan objek, dan selanjutnya proses perbaikan segera dilakukan untuk mendapatkan hasil yang baik sesuai dengan model yang telah dirancang sebelumnya.

\section{KESIMPULAN}

Dari laporan yang telah diuraikan pada bab-bab sebelumnya, maka dapat diambil beberapa kesimpulan :

1.Unified Modeling Language memberikan visualisasi serta panduan yang jelas dalam proses perancangan perangkat lunak MP3 Player, hingga dapat terealisasi program yang dapat menjalankan file mp3 untuk didengarkan melalui perangkat komputer multimedia.

2.Tombol-tombol yang terdapat pada tampilan utama program MP3 Player dapat berjalan dengan baik dan benar sesuai dengan perancangan yang dibuat, tombol- tombol tersebut berjalan sesuai dengan fungsi serta prosedur yang diberikan.

3.Selain tombol-tombol terdapat animasi berupa visualizer yang menunjukkan bahwa musik sedang diputar untuk menambah kesan menarik pada ti4ePlayer.

\section{SARAN}

Setelah menyelesaikan laporan tugas akhir ini, penulis dapat memberikan saran-saran demi proses pengembangan selanjutnya, antara lain :

1.Membuat tampilan utama MP3 Player lebih menarik dengan penambahan fasilitas skin browser dan bentuk-bentuk animasi pada saat program dijalankan.

2.Menambah fitur MP3 Player lebih banyak, yaitu informasi lagu yang sedang dijalankan antara lain : judul lagu, tahun penciptaan, jenis musik, dan lain-lain

\section{Daftar Pustaka}

[1] Presented by Noe Penelope, The Unified Software Development Process, San Antonio SPIN, 8 November 2000.

[2] Pressman Roger S., Software Engineering : A Practitioner's Approach, Third Edition, McGrawHill Inc., Singapore, 1992.

[3] Rosa \& Shalahudin, Rekayasa perangkat lunak terstruktur dan berorientasi objek). Modula:Bandung (2011)

[4] Raphael Kang, MP3-2000.com : 27 Mei 2001. 